\title{
An Experimental Study of Composite Plain Bearings: The Influence of Clearance on Friction Coefficient and Temperature
}

\author{
Daniel Miler1 - Stanko Škec ${ }^{1,2^{*}}$ - Branko Katana ${ }^{1}$ - Dragan Žeželj1 \\ 1 University of Zagreb, Faculty of Mechanical Engineering and Naval Architecture, Croatia \\ 2 Technical University of Denmark, Denmark
}

Plain bearings are often used due to their compact dimensions and low cost. Their frictional and wear properties are affected by several parameters: load, sliding velocity, temperature, and surface roughness, among others. In this article, the authors have experimentally investigated the influence of clearance size on the friction and wear in composite plain bearings. An experimental rig was designed to enable the testing of plain bearings in working conditions similar to those encountered throughout their exploitation. Two load levels, two lubrication types, and four clearance levels were varied, resulting in 48 experiments, as each was replicated twice. The friction coefficient and bearing temperature were measured during the experiment, while the material loss and change in surface roughness were determined postexperiment. The results have shown that clearance affects the friction in both the dry running specimens and specimens lubricated using a solid lubricant (polytetrafluoroethylene).

Keywords: clearance, composite, friction coefficient, plain bearing.

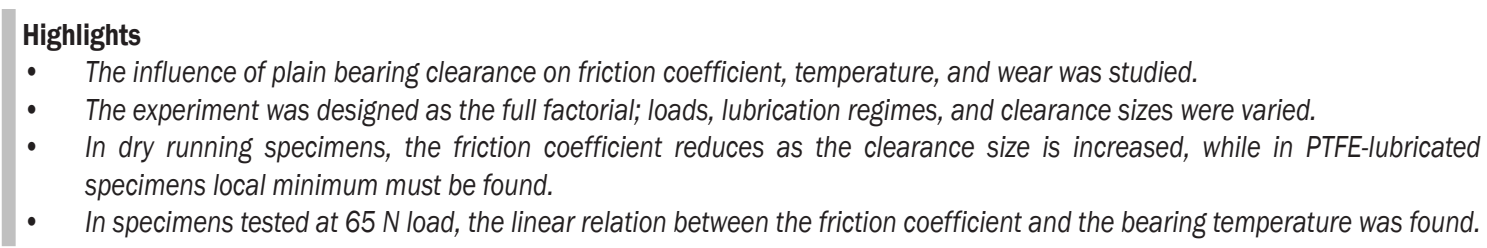

\section{O INTRODUCTION}

The bearings enable relative linear or rotational motion between the two parts by reducing the friction coefficient. Plain bearings are a frequently used bearing sub-type, most likely due to their fairly simple geometry and low manufacturing cost. Since no additional rolling elements are required, their outer diameter is small, while the large contact surface increases the load-carrying capacity. The performance of a plain bearing can be evaluated through a number of criteria, such as its efficiency [1], durability [2], or load-carrying capacity [3]. As such, it is influenced by several parameters: load, sliding velocity, operating temperature, surface roughness, clearance between the plain bearing and the shaft [4], and material.

Composite materials are often used in the design of machine elements to provide engineers with a wider range of possibilities in terms of material mechanical properties. The composites have diverse mechanical properties, which are usually achieved by combining different matrix, filler, and reinforcement materials. For example, polymer matrices are chemically resistant but are adversely affected by an increase in temperature. As noted by Prehn et al. [5], a chemically resistant polymer matrix (polyetheretherketone and epoxy resin were used in the referenced study) embedded with fibre reinforcement (CF) and filler $(\mathrm{SiC})$ has improved wear properties while also enabling use in adverse environments, such as seawater [6]. Further, the working temperature often narrows the suitable matrix materials to thermally resistant ones; for example, an increase in temperature decreases the mechanical properties of polymers [7], such as the tensile strength, permissible Hertzian stress, and Young modulus, rendering them unusable. Increase in temperature reduces the tensile strength, permissible Hertzian (contact) stress, and Young modulus of polymer materials. Building on these premises, a compromise during the selection of composite materials may be required to achieve the desired bearing properties, such as the high load capacity or low power losses.

As a plain bearing material, composites have several advantages when compared to the traditionally used bronze alloys [8]: higher chemical resistance, lower wear rate, vibration damping, and lower weight. For that reason, there has been a steady rise in composite use for plain bearing manufacturing. It should be noted that the composites used as plain bearing materials are thermal insulators, meaning that an increase in the working temperature will be higher. Moreover, to better understand the overall performance and limitations of the composite plain 
bearings, most of the current research efforts are focused on the analysis of tribological properties [9] and [10], the optimization of design itself [11] and [12], application of novel materials and coatings [13] and [14], or studying the lubrication models [15].

Generally, the research on tribological properties includes studying the adhesion, friction, wear, and lubrication of surfaces in contact [16]. The tribological properties of the composite materials such as the friction coefficient and wear rate can be improved by altering the orientation, volume fraction, and shape of the reinforcements. For example, El-Sayed et al. [17] found that, for the observed composite material, the lowest friction coefficient is achieved using either transversal or longitudinal fibre orientation. Moreover, increased volume fraction was found to have a beneficial effect on both the wear rate and friction coefficient. By varying the whisker aspect ratios, $\mathrm{Ji}$ et al. [18] determined whether the reinforcement shape affects the frictional and wear properties of the composite. Whiskers with lower aspect ratios resulted in more stable mechanical properties. Masripan et al. [19] studied the effect of hardness on a plain bearing's tribological properties. The authors concluded that using the hardest test specimen will result in the lowest friction and, consequently, the lowest wear. The design can be enhanced by altering the microgeometry; with surface texturing being one of the methods. Rahmani and Rahnejat [12] used analytical methods to optimize texture geometry of composite reinforcements. Orientation and layout of the surface fibre were varied to increase the load capacity.

When aiming to improve the performance of a bearing-shaft system, in addition to the design and material selection, the use of lubricant is essential. It reduces the friction and material wear in plain bearings and, consequently, improves their efficiency and service life [20]. The lubricants can be either liquid (greases, oils), solid or gaseous. In composite materials with a polymer matrix, lubricants can be impregnated into the matrix, or the running can be dry (no lubricant). This research study is focused on solid lubricants, which are most often used when a continuous adherent film is required in the rubbing surfaces [21], a case encountered in plain bearings. The key advantage to solid lubricants in bearing design is simplicity; there is no need for a lubricating system. Additionally, they ensure uniform friction coefficient and increased permissible contact stresses at the cost of a limited lifetime and modest heat dissipation properties [22]. For lubrication of polymer materials the diamond-like carbon (DLC), polytetrafluoroethylene (PTFE), and $\mathrm{MoS}_{2}$ are the most widely used solid lubricants, with PTFE often described as promising [23].

For the dry running specimen, Rezaei et al. [4] conducted an experimental study using the oscillatory motion, often found in mechanical joints. The clearance was found to have a significant impact on the contact stress distribution. No further studies considering the influence of clearance on dry running plain bearings were found.

For this reason, in this article, the authors investigated whether the clearance has an influence on friction coefficient and wear in plain bearings operating at constant rotational speed, as found in mechanical transmissions. The rotational shaft movement was used instead of the oscillatory one to more precisely simulate a bearing-shaft system [4].

\section{METHODS}

The main goal of this experimental study was to determine how the clearance affects the friction coefficient between the bearing and shaft, and the wear of the composite bearing itself. The experimental rig is described in Section 2, while the variables of interest and associated levels are given in Section 2.1.

The plain bearing specimens made of NORDEN Marine 605 composite are coupled with the shaft made of AISI 316. The composite consists of a thermosetting resin reinforced with synthetic fabric and impregnated with solid lubricants to enhance the dry running capabilities. As such, it is an orthotropic material. Its mechanical properties are shown in Table 1. Additional manufacturer-provided data that includes the composite material specifications, machining recommendations, and handling information can be found in [24].

The influence of clearance on the composite plain bearing performance regarding the bearing efficiency and durability was assessed for both the dry running and lubricated specimens. Solid lubricants were applied instead of the liquid ones to avoid the swelling of the polymer matrix. Within the study, polymer swelling is undesirable since it affects the clearances that must remain the same during the test run. PTFE was selected as a lubricant due to its tribological properties (low friction) and convenient application.

The conducted study is based on the approach used by Rezaei et al. [4], who studied the clearance influence on the contact stresses in polymeric composite journal bearings. Rezaei et al. conducted an experiment using two different bearings, each having a different vertical load, clearance, and width. PTFE filler was used as a lubricant in both bearings. 
In this research study, a full factorial experimental design was used (more details in Section 2.2). Two lubrication types were combined with two load and four clearance levels, resulting in a total of 16 required measurements per replication. Three replications were made for each specimen to obtain statistically relevant data. Each measurement lasted 120 minutes to avoid the transitional phenomena, thus ensuring the robustness of results. Level selection is explained in Section 2.1.

Table 1. NORDEN Marine 605 mechanical properties [24]

\begin{tabular}{lc}
\hline Property & \\
\hline Maximum tensile strength $\left[\mathrm{N} / \mathrm{mm}^{2}\right]$ & 60 \\
\hline Maximum safe static load $\left[\mathrm{N} / \mathrm{mm}^{2}\right]$ & 110 \\
\hline Maximum safe dynamic load $\left[\mathrm{N} / \mathrm{mm}^{2}\right]$ & 55 \\
\hline Density $\left[\mathrm{kg} / \mathrm{m}^{3}\right]$ & 1300 \\
\hline Maximum water swell $[\%]$ & 0.15 \\
\hline Maximum working temperature $\left[{ }^{\circ} \mathrm{C}\right]$ & 100 \\
\hline
\end{tabular}

\section{EXPERIMENTAL}

The experimental rig was created to emulate the working conditions, and the loads plain bearings have to endure during their working life (Fig. 1). The rig enables the adjustment of bearing load $F_{\mathrm{w}}$ by using weights, which are attached to the ball bearing to keep a constant orientation of load vector. The ball bearing is fitted on the outer side of the plain bearing housing, as shown in Fig. 1. The torque $T$ used to overcome the frictional losses is provided by an alternating current (AC) electric motor and is measured using the torque meter. The torque meter of accuracy class 0.2 and a nominal torque of $20 \mathrm{Nm}$ was used. A plain bearing is mounted in the housing using the press fit.

The shaft diameter is $34 \mathrm{~mm}$. During the experiment, the rotational speed of the shaft is constant. The rotation causes relative movement between the static plain bearing and the shaft. At the end of the upper rig arm, a load cell (accuracy class 0.2 , a nominal force of $500 \mathrm{~N}$ ) is mounted to enable the measurement of force $F_{\mathrm{m}}$. Sensors were connected to the data acquisition unit operating using professional software.

The rig geometry is defined as follows; the distance $L=150 \mathrm{~mm}$ is the distance between the shaft axis and the load cell. An increase in length $L$ enables the use of a lower capacity load cell, the advantage of which is higher test rig accuracy, as the cell sensitivity is specified as a percentage of the maximum capacity.

Due to a higher thermal expansion coefficient of the polymer matrix composites, an increase in temperature will result in a larger decrease in the clearance, when compared to the steel parts. A thermometer has been installed to keep track of the change in temperature, which causes thermal expansion. The highest temperature is expected in the contact zone between the bearing and shaft, where it cannot be measured directly. For this reason, the thermometer beam is focused on the plain bearing side, near the contact point. The contactless thermometer (declared accuracy of $\pm 1 \%$ ) was used to measure the plain bearing temperature $\vartheta$. The disadvantages of using the above-described method to determine the polymer temperature are shown in [25].

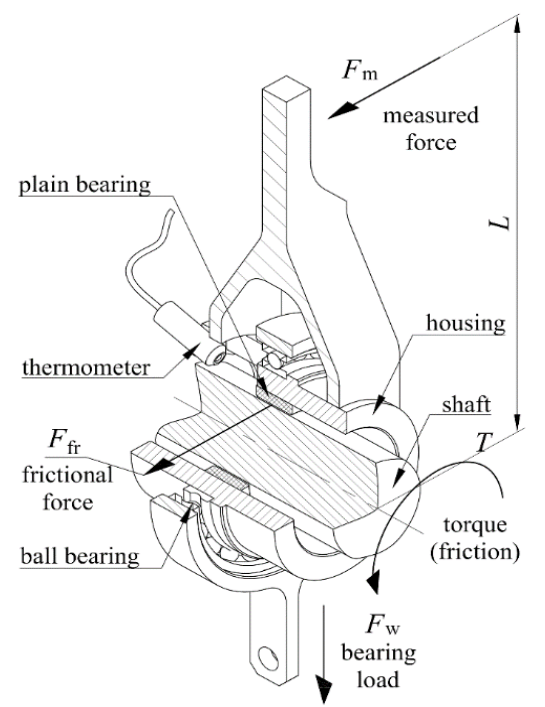

Fig. 1. Experimental rig

\subsection{Experimental Variables}

Preliminary variable analysis and selection were necessary due to a limited number of runs. The experimental variables can be divided into three groups: independent variables, dependent variables, and control variables. Independent variables serve as input and are manipulated to determine their influence on the dependent variables, which is measured throughout the experiment, while the control variables remain unchanged to prevent them from affecting the results. Influences of the following independent variables were considered in this experimental study:

Clearance - the primary aim of the study was to conclude whether the clearance influences the plain bearing friction and wear. The clearance size $S$, defined as the difference between the internal bearing and shaft diameter, was varied. Bearings were made with bore widths of $34.15 \mathrm{~mm}, 34.25 \mathrm{~mm}, 34.5 \mathrm{~mm}$, 
and $34.9 \mathrm{~mm}$, resulting in clearances of $0.15 \mathrm{~mm}, 0.25$ $\mathrm{mm}, 0.5 \mathrm{~mm}$ and $0.9 \mathrm{~mm}$ respectively. To diminish the influence of manufacturing error on the experimental results, specimens were measured before the experiment. An internal micrometer with a precision of $0.001 \mathrm{~mm}$ was used.

Bearing load - is equal to the radial force applied to the bearing through the shaft. It is included as an independent variable since, at both ends of the load spectrum (light and heavy loads), load effect on the friction coefficient was found. The former was presented by Myshkin et al. [26] in a review article, in which an overview of research articles studying load influence on friction in various polymers was shown, mostly using the ball-on-disc method. For light loads, the friction decreases as the load increases, while the opposite is correct for the heavy loads [27]. Since the Norden Maritim 605 has a polymer matrix, results are relevant to the case observed in the study at hand. To account for bearing load $\left(F_{\mathrm{w}}\right)$ influence, two load levels were used. A load of $65 \mathrm{~N}$ was chosen to represent the regular working load, while $115 \mathrm{~N}$ represents the higher end of the load spectrum.

Lubrication - the lubricant is used to reduce the friction coefficient between the two parts in relative motion and as such influences the friction coefficient. Thus, the two lubrication types were included as independent variables; the dry running specimens were compared to specimens lubricated using a solid lubricant, PTFE. It should be emphasized that the lack of oil film in solid lubrication eases the thermometer beam focusing.

The following dependent variables were measured or calculated during the experiment:

Friction coefficient - is one of the key factors for assessing the efficiency of a power transmission [28]; reducing the friction coefficient will result in lower power losses. The defined test rig geometry (moment arm lengths $L$ and $r$ ) and the known forces $F_{\mathrm{m}}$ and $F_{\mathrm{w}}$ enable the friction coefficient calculation using Eq. (1), as follows:

$$
\mu=\frac{F_{\mathrm{m}} \cdot L}{F_{\mathrm{w}} \cdot r},
$$

where $F_{\mathrm{m}}[\mathrm{N}]$ is the load cell measured load; $L$ [mm] the distance between the shaft axis and the load cell; $r[\mathrm{~mm}]$ the inner plain bearing radius, and $F_{\mathrm{w}}[\mathrm{N}]$ the applied weight.

Temperature - is known to affect the friction coefficient between the parts [26]. Moreover, an increase in the temperature causes thermal expansion, reducing the previously measured clearances. The low thermal conductivity of the matrix should also be noted, as the expected contact temperature could be higher than the measured one. To enable the assessment of thermal influence on the friction coefficient, it is selected as a dependent variable and tracked throughout the experiment. As described in Section 2, a contactless thermometer was used to measure the change in temperature close to the point of contact. By keeping track of the changes in temperature, it is possible to determine the magnitude of thermal expansion.

Wear - to determine the influence of the clearance on composite plain bearing wear, specimens were weighed before and after the experiment [29]:

$$
\Delta m=m_{\text {initial }}-m_{\text {final }},
$$

where $m_{\text {initial }}[\mathrm{mg}]$ and $m_{\text {final }}[\mathrm{mg}]$ are bearing masses before and after the experimental run, respectively. The digital scale with an accuracy of $0.001 \mathrm{~g}$ was used to weigh the specimens. The PTFE-lubricated specimens were weighed before and after lubrication.

Surface roughness - although the influence of surface roughness on the friction coefficient exists, as demonstrated in [30], it was not considered in this study. However, mean surface roughness was measured before and after the experiment to keep track of the smoothing effect. All the specimens were to be manufactured with the equal mean surface roughness of $R a=3.2 \mu \mathrm{m}$. Its values are measured in the axial direction before and after the experiment to provide data for possible future studies. The authors used a roughness tester with a resolution of $0.002 \mu \mathrm{m}$ at a $25 \mu \mathrm{m}$ range.

Lastly, the following variables were chosen as constants:

Sliding velocity - the sliding velocity influences both the friction and wear [8], but was not considered within this research study. According to Myshkin, et al. [26], for insignificant variations in contact temperature, independence of friction coefficient in relation to the sliding velocity can be assumed. The sliding velocity $v_{\mathrm{s}}=0.53 \mathrm{~m} / \mathrm{s}$ was selected for all the specimens. Temperature measurements were used for the validation of the sliding velocity simplification procedure.

Bearing width - plain bearing width was $27 \mathrm{~mm}$ for all test specimens.

Outer bearing diameter - a value of $39 \mathrm{~mm}$ was used for all the test specimens. 


\subsection{Design of Experiment}

The experiment was organized as full factorial since it was difficult to predict the possible interactions between variables, and whether there are saddle points within the interval at hand. The clearance size, lubrication, and bearing load selected as independent variables (see Fig. 2). Additionally, measurements were replicated twice to increase the reliability, resulting in a total of 48 experimental runs.

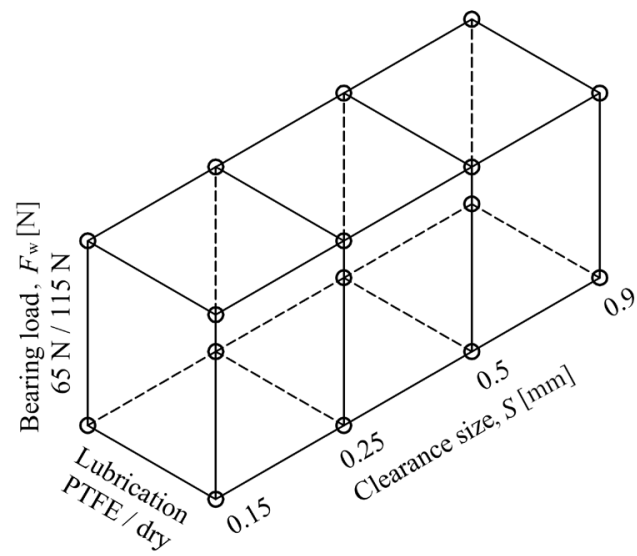

Fig. 2. Design of experiment schema

The clearances between the shaft and the bearings were measured to determine the scale of manufacturing error (see Table 2).

Table 2. Clearances

\begin{tabular}{|c|c|c|c|c|c|}
\hline \multirow{2}{*}{$\begin{array}{l}\text { Lubri- } \\
\text { cation }\end{array}$} & \multirow{2}{*}{$\begin{array}{l}\text { Bearing } \\
\text { load, } \\
F_{\mathrm{w}}[\mathrm{N}]\end{array}$} & \multirow{2}{*}{$\begin{array}{l}\text { Theoretical } \\
\text { clearance } \\
S_{\mathrm{th}},[\mathrm{mm}]\end{array}$} & \multicolumn{3}{|c|}{ Measured clearance $S$, [mm] } \\
\hline & & & 1 & ॥ & III \\
\hline \multirow{8}{*}{ 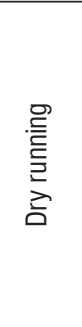 } & \multirow{4}{*}{65} & 0.15 & 0.128 & 0.13 & 0.133 \\
\hline & & 0.25 & 0.224 & 0.235 & 0.243 \\
\hline & & 0.5 & 0.511 & 0.52 & 0.562 \\
\hline & & 0.9 & 0.866 & 0.872 & 0.882 \\
\hline & \multirow{4}{*}{115} & 0.15 & 0.145 & 0.17 & 0.19 \\
\hline & & 0.25 & 0.224 & 0.241 & 0.246 \\
\hline & & 0.5 & 0.532 & 0.535 & 0.541 \\
\hline & & 0.9 & 0.91 & 0.918 & 0.919 \\
\hline \multirow{8}{*}{ 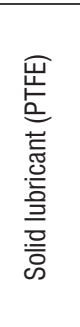 } & \multirow{4}{*}{65} & 0.15 & 0.145 & 0.147 & 0.147 \\
\hline & & 0.25 & 0.241 & 0.242 & 0.243 \\
\hline & & 0.5 & 0.532 & 0.535 & 0.536 \\
\hline & & 0.9 & 0.917 & 0.918 & 0.93 \\
\hline & \multirow{4}{*}{115} & 0.15 & 0.165 & 0.168 & 0.186 \\
\hline & & 0.25 & 0.251 & 0.253 & 0.282 \\
\hline & & 0.5 & 0.505 & 0.55 & 0.58 \\
\hline & & 0.9 & 0.925 & 0.935 & 0.94 \\
\hline
\end{tabular}

\section{RESULTS}

A total of 48 measurements have been carried out. All the specimens were inspected after the experiment to avoid erroneous measurements. The inspection procedure consisted of disassembling the experimental rig and removing the test specimen, which was then cleaned using the solvent cleaner. After the cleaning, visual inspection using a magnification lens was carried out. During the visual inspection, the focus was on detecting failure modes caused by the manufacturing process or inaccurate assembly (i.e. uneven wear). Failure modes that develop slowly, such as corrosion or fatigue failure were not considered since the experiment lasted for only 120 minutes. Uneven wear was the only defect the authors detected within the study. The authors assume that it was caused by a misalignment of the plain bearing and shaft axes. For all the specimens where a defect was detected, a measurement was repeated.

The relation between the friction coefficient, the plain bearing temperature, and the clearance is shown in Fig. 3 (for additional plots see Appendix, Fig. 7). Dry running specimens displayed inconclusive results; trends were not consistent for loads of $65 \mathrm{~N}$ and 115 $\mathrm{N}$. In the former, greater clearance caused a decline in the friction coefficient. Measurements on clearances of $0.25 \mathrm{~mm}$ and $0.5 \mathrm{~mm}$ found no significant difference in friction coefficient. For the load of 115 $\mathrm{N}$, friction coefficients displayed a different trend. The lowest friction coefficient $\mu=0.184$ was found at the $0.15 \mathrm{~mm}$ clearance, followed by $\mu=0.192$ at the $0.9 \mathrm{~mm}$ clearance. In PTFE-lubricated specimens, results are consistent for both load levels. The highest friction coefficient was found at the clearance of 0.15 $\mathrm{mm}$. With the increase in clearance, up to $0.5 \mathrm{~mm}$, the friction coefficient was reduced. The change was more prominent for the higher load level; the lowest friction coefficient values were measured for clearance of 0.5 $\mathrm{mm}$. Further increase in the clearances resulted in an increased friction coefficient. Lastly, when compared to the PTFE-lubricated specimens, the calculated friction coefficients were higher for the dry running specimens.

As shown in Fig. 3, changes in the measured temperatures are related to the changes in friction coefficient. The relationship is the most prominent for dry running specimens under the load of $65 \mathrm{~N}$. The exceptions were $0.15 \mathrm{~mm}$ clearances, for which no relation with the friction coefficient was found. The largest deviations were found in dry running specimens loaded with $65 \mathrm{~N}$ and the lubricated specimen loaded with $115 \mathrm{~N}$. Dry running specimens displayed similar 
behaviour at both load levels except for $0.15 \mathrm{~mm}$ clearance. Increase in the clearances resulted in minor decreases in the temperatures. For the PTFE-lubricated specimens, the highest temperatures were measured at the clearance of $0.15 \mathrm{~mm}$. Increases in clearance resulted in lower temperatures up to clearance of 0.5 $\mathrm{mm}$; the lowest temperature was measured for both load levels. Further increase in clearance resulted in increased temperature. On average, the difference in measured temperature between the dry running and PTFE-lubricated specimens was $4.26{ }^{\circ} \mathrm{C}$ at the load level of $65 \mathrm{~N}$, and $4.35^{\circ} \mathrm{C}$ at $115 \mathrm{~N}$. When comparing the load level influence on the temperatures, the average difference in temperature between the $115 \mathrm{~N}$ and $65 \mathrm{~N}$ load was $7{ }^{\circ} \mathrm{C}$ for dry running and $6.7^{\circ} \mathrm{C}$ for PTFE-lubricated specimens.

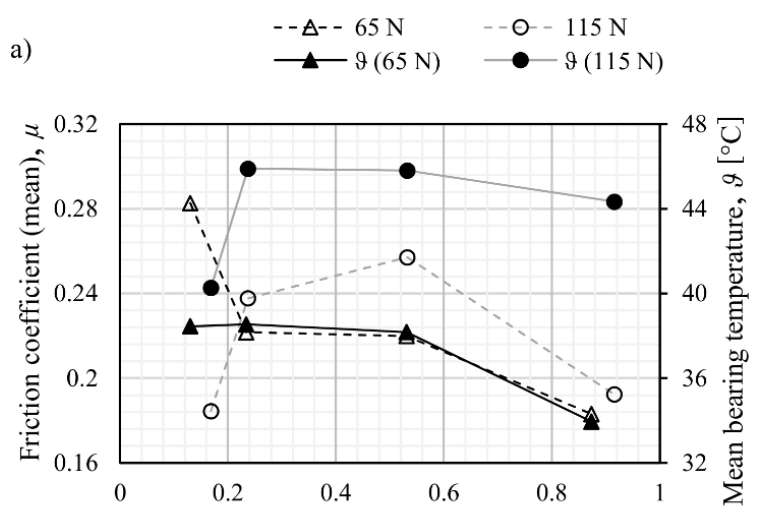

b)

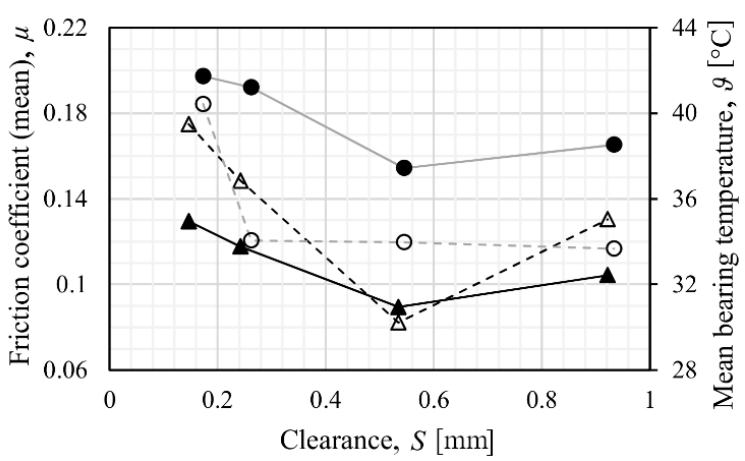

Fig. 3. Influence of clearance on a friction coefficient and temperature a) dry running and b) PTFE-lubricated

The weighing of specimens has shown that clearance has an impact on bearing wear (Fig. 4). By using the experiment data, the average mass loss was calculated for each test condition. As expected, higher wear is measured in dry running specimens at both load levels; on average, usage of the PTFE lubricant reduced the lost material mass by $1 \mathrm{mg}$ for $65 \mathrm{~N}$ and $0.66 \mathrm{mg}$ for $115 \mathrm{~N}$ load. The lowest wear was found in
$0.5 \mathrm{~mm}$ clearance bearings for both lubrication regimes and load levels. When compared to $0.9 \mathrm{~mm}$ clearance, using $0.15 \mathrm{~mm}$ and $0.25 \mathrm{~mm}$ clearances causes a more prominent increase in wear. When comparing the influence of load levels, dry running specimens displayed inconclusive results. For clearance of 0.15 $\mathrm{mm}$, lower load resulted in lower wear, while for the $0.25 \mathrm{~mm}$ and $0.5 \mathrm{~mm}$ clearances higher load coincided with the lower wear. At the $0.9 \mathrm{~mm}$ clearance, average mass losses due to wear were equal. The behaviour observed in PTFE-lubricated specimens was similar; at clearances of $0.15 \mathrm{~mm}$ and $0.5 \mathrm{~mm}$, lower wear was recorded for $65 \mathrm{~N}$ load, in contrast to $0.25 \mathrm{~mm}$ and $0.9 \mathrm{~mm}$ clearances, which favoured the higher load. As noted in Section 2.1, mean surface roughness was measured both before and after the experiment. For the dry running specimens, the average change in mean surface roughness was $0.87 \mu \mathrm{m}$ at $65 \mathrm{~N}$, and $0.89 \mu \mathrm{m}$ at $115 \mathrm{~N}$. Lubricated specimens displayed greater smoothing effect; average change in mean surface roughness was $1.56 \mu \mathrm{m}$ at a load of $65 \mathrm{~N}$ and $1.28 \mu \mathrm{m}$ at $115 \mathrm{~N}$.

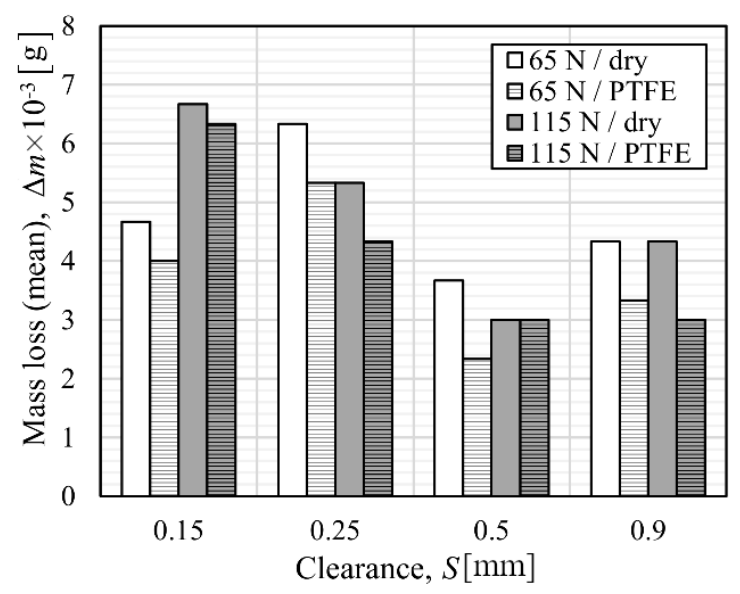

Fig. 4. Bearing mass loss for different clearances

\section{DISCUSSION}

In plain bearings working under constant rotational speed, the clearance size affects the friction coefficient, differing from the results for oscillating movement presented in [4]. For example, at $65 \mathrm{~N}$ loads, the lowest friction coefficient was measured for $0.5 \mathrm{~mm}$ clearance. In the vicinity of that value lays the optimal clearance for a corresponding set of selected parameters. By either increasing or decreasing the clearance, the friction coefficient increases.

Lowering the clearance size results in an increase in the friction coefficient, thus increasing 
the risk of bearing failure. The former statement was validated by repeating the experiment for the bearings with clearances of $0.05 \mathrm{~mm}$ (Fig. 5). Each test run, regardless of load level and lubrication regime, resulted in bearing seizure within the first hour. The average friction coefficients for the duration of the experiment were ranging from 0.782 to 0.819 for dry running and from 0.636 to 0.65 for PTFElubricated specimens. Similar results were reported by Brockwell and DeCamillo in [31], where a small decrease in clearance size resulted in a steep increase of the temperature, restricting the rotational velocities.

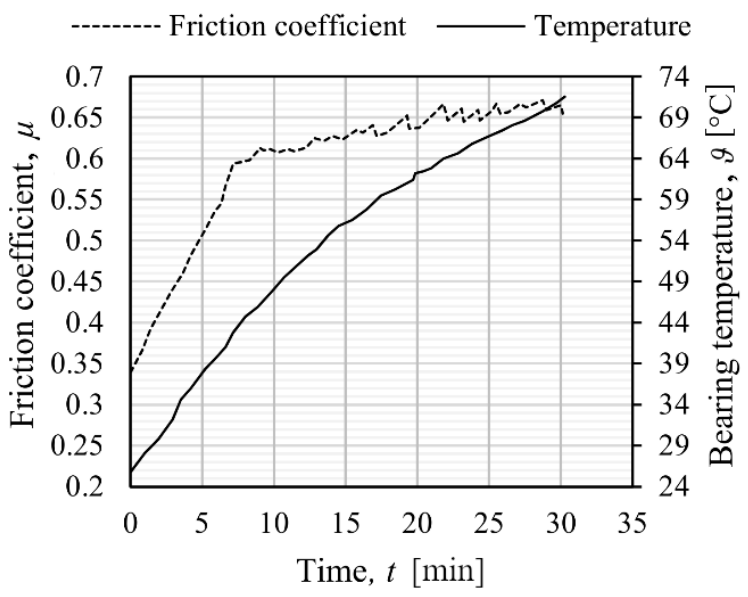

Fig. 5. Results for PTFE-lubricated specimen (115 N)

On the other side of the spectrum, for the dry running specimens, the increase in clearance size resulted in a lower friction coefficient. In PTFElubricated specimens, however, larger clearance sizes also resulted in higher friction coefficients. With an increase in clearance size, contact surface decreased, causing the contact pressure to rise. Using the procedure presented in [32], in specimens loaded with $65 \mathrm{~N}$ contact pressure of $0.8 \mathrm{MPa}$ was calculated for $0.15 \mathrm{~mm}$, and $1.9 \mathrm{MPa}$ for $0.9 \mathrm{~mm}$ clearance. At a higher load level, values were $1 \mathrm{MPa}$ and $2.5 \mathrm{MPa}$, respectively. It should be added that a study carried out by Domitran, et al. [25], in which the authors used polyethylene (PET) samples with the addition of PTFE, has shown that an increase in contact pressure also increased the friction coefficient. Building on these premises, an increase in contact pressure could affect the increase in friction coefficient in lower clearance sizes. When assessing the relationship between the bearing load and friction coefficient, higher friction coefficients were calculated for higher loads, regardless of the lubrication regime.

Furthermore, the friction coefficient trendlines in dry running specimens had a similar shape for
$65 \mathrm{~N}$ and $115 \mathrm{~N}$ loads. The same was found in PTFE-lubricated specimens. Exceptions to former statements were the dry running specimens with 0.15 $\mathrm{mm}$ clearance and PTFE-lubricated specimens with $0.25 \mathrm{~mm}$ clearance. The differences regarding the lubrication regime were also noted. In dry running specimens, the lower friction coefficient was achieved by increasing the clearance size. For PTFE-lubricated specimens, optimal clearance must be found. The optimal clearance will be a trade-off between the seizure at the low clearance sizes and an increase in contact pressure in higher clearance sizes.

The clearance affects the temperature of bearing near the contact point (Fig. 5). However, those changes are low; the largest difference in temperature $\Delta \vartheta_{\max }=5.6{ }^{\circ} \mathrm{C}$ was measured for bearings operating at $115 \mathrm{~N}$ load with no lubricant. Accordingly, as the $\Delta \vartheta_{\max }$ is rather low and comparable to the fluctuations in the ambient temperature, the assumption regarding the use of constant sliding velocity is valid (see Section 2.1, [26]). The bearing load was also shown to affect the bearing temperature. In specimens loaded with $65 \mathrm{~N}$ loads, changes in clearance size resulted in a linear relationship between the friction coefficients and measured bearing temperature (Fig. 6). It was more prominent in PTFE-lubricated specimens, likely due to a more uniform surface resulting from the application of solid lubricant. No distinct trends were noted for the specimens operating under a heavier load. The lower friction coefficient results in a lower frictional force, which in turn reduces the amount of heat transferred to the bearing and its wear. Consequently, the lower temperature was measured in PTFE-lubricated specimens. By further increasing the clearance size to $0.9 \mathrm{~mm}$, the temperature started to increase. For the dry running specimens, the bearing temperature decreased with the increase in clearance.

The lowest mass loss was measured for $0.5 \mathrm{~mm}$ clearances, which proved to be optimal regarding the wear for all the specimens. Furthermore, with the increase of clearance size from $0.15 \mathrm{~mm}$ to $0.5 \mathrm{~mm}$, mass loss in specimens working under $115 \mathrm{~N}$ load decreased, after which it rose at a clearance of $0.9 \mathrm{~mm}$. The similar behaviour was observed in the friction coefficient. For loads of $65 \mathrm{~N}$, highest wear was found in $0.25 \mathrm{~mm}$ clearances. It was also observed that, contrary to the higher load level, specimens working at $65 \mathrm{~N}$ load have multiple local minima, suggesting the need for including additional clearance size levels in the future studies. 


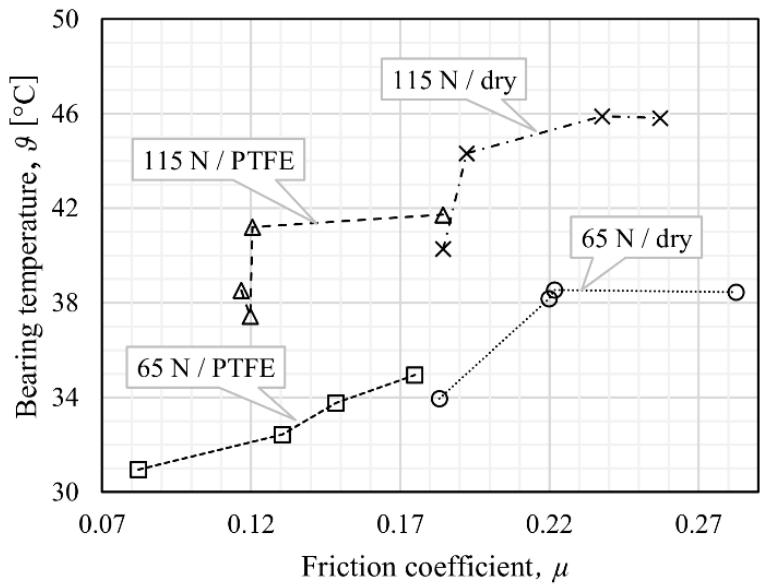

Fig. 6. Relationship between the friction coefficient and bearing temperature (not sequenced by the clearance)

Similarly to the friction coefficient and temperature, the higher load caused more intensive wear. The larger frictional force, caused by higher friction coefficient and normal load, resulted in more intensive bearing wear. Thus, it was expected that a mass loss will increase as the friction coefficient increases. However, the experimental results were not in agreement with the former statement; even though the increase in wear is expected as the load level rises [33], no consistency in mass loss depending on the load was found. The use of lubricant resulted in lower wear for all the clearances and load levels, as expected. The mass loss reduction was lower for the higher bearing load. When considering the surface roughness, even though the lowest average values were found in 0.5 $\mathrm{mm}$ clearance specimens, differences were rather modest. No bearing load impact was observed as the lowest change was recorded in the dry running specimens at $65 \mathrm{~N}$ load.

\section{CONCLUSIONS}

The study of the influence of clearance on the friction coefficient and wear in composite plain bearings has been carried out. A total of 48 experimental measurements have been conducted. The performances of composite plain bearings manufactured with different clearances were observed under two levels of load and two different lubrication regimes; dry running and solid lubricant applied (PTFE). Not accounting for the manufacturing error, four different clearances were observed.

The results have shown that the friction coefficient is affected by clearance. For the dry running specimens, the results have shown that the friction coefficient reduces as the clearance size is increased. In PTFE-lubricated specimens, the optimum must be found, as the local friction coefficient minimum was found inside the observed clearance size interval. When considering the bearing temperature, in specimens tested under the $65 \mathrm{~N}$ loads, the linear relation between the friction coefficient and the bearing temperature was found. The relation between the temperature and friction coefficient was found only at the lower load level $(65 \mathrm{~N})$, while no general trends were observed for the wear and surface roughness change.

Even though the study has shown that clearance affects the friction coefficient, temperature, and wear in dry running and PTFE-lubricated specimens, initial results point out that the further work is required to determine its optimal values. By decreasing the interval between the different clearance size levels, the optimal solution could be found. Increase of a number of clearance size levels could mitigate the possible saddle points found when observing wear.

\section{ACKNOWLEDGEMENTS}

This paper reports on work funded by the Croatian Science Foundation project IP-2018-01-7269: Team Adaptability for Innovation-Oriented Product Development (TAIDE).

\section{NOMENCLATURES}

$b \quad$ bearing width, $[\mathrm{mm}]$

$F_{\mathrm{m}} \quad$ measured force, $[\mathrm{N}]$

$F_{\text {w }}$ bearing load, [N]

$F_{\text {fr }} \quad$ frictional force, [N]

$L \quad$ distance between the load cell and shaft axis, [mm]

$\Delta m \quad$ plain bearing mass loss, $[\mathrm{g}]$

$r \quad$ inner bearing radius, [mm]

$\Delta R a$ difference between the initial and final mean surface roughness, $[\mu \mathrm{m}]$

$S \quad$ clearance between the plain bearing and the shaft, [mm]

$T$ motor-provided torque, [Nm]

$v_{\mathrm{S}} \quad$ sliding velocity, $[\mathrm{m} / \mathrm{s}]$

$\vartheta \quad$ bearing temperature, $\left[{ }^{\circ} \mathrm{C}\right]$

$\mu \quad$ friction coefficient, [-] 


\section{REFERENCES}

[1] Hirani, H., Suh, N.P. (2005). Journal bearing design using multiobjective genetic algorithm and axiomatic design approaches. Tribology International, vol. 38, no. 5, p. 481-491, D0l:10.1016/j.triboint.2004.10.008.

[2] Schmidt, A.A., Schmidt, T., Grabherr, O., Bartel, D. (2018). Transient wear simulation based on three-dimensional finite element analysis for a dry running tilted shaft-bushing bearing. Wear, vol. 408-409, p. 171-179, D0l:10.1016/j. wear.2018.05.008.

[3] Shinde, A.B., Pawar, P.M. (2017). Multi-objective optimization of surface textured journal bearing by Taguchi based Grey relational analysis. Tribology International, vol. 114, p. 349357, D0I:10.1016/j.triboint.2017.04.041.

[4] Rezaei, Van Paepegem, W., Ost, W., De Baets, P., Degrieck, J. (2012). A study on the effect of the clearance on the contact stresses and kinematics of polymeric composite journal bearings under reciprocating sliding conditions. Tribology International, vol. 48, p. 8-14, D0l:10.1016/j. triboint.2011.06.031.

[5] Prehn, R., Haupert, F., Friedrich, K. (2005). Sliding wear performance of polymer composites under abrasive and water lubricated conditions for pump applications. Wear, vol. 259, no 1-6, p. 693-696, D0l:10.1016/j.wear.2005.02.054.

[6] Chen, B., Wang, J., Yan, F. (2012). Comparative investigation on the tribological behaviors of CF/PEEK composites under sea water lubrication. Tribology International, vol. 52, p. 170177, D0I:10.1016/j.triboint.2012.03.017.

[7] VDI 2736-2:2014. Thermoplastic Gear Wheels - Cylindrical Gears - Calculation of The Load-Carrying Capacity, Verlag des Vereins Deutscher Ingenieure, Düsseldorf.

[8] Opalić, M., Domitran, Z., Katana, B. (2014). Comparison of Antifriction Properties of Polymer Composites and Bronze. Tehnički Vjesnik - Technical Gazette, vol. 21, no. 5, p. 10891095.

[9] Eliezer, Z., Khanna, V.D., Amateau, M.F. (1978). Wear mechanism in composites: a qualitative model. Wear, vol. 51, no. 1, p. 169-179, DOI:10.1016/0043-1648(78)90064-9.

[10] Rezaei, Van Paepegem, W., De Baets, P., Ost, W., Degrieck, J. (2012). Adaptive finite element simulation of wear evolution in radial sliding bearings. Wear, vol. 296, no. 1-2, p. 660-671, Dol:10.1016/J.wear.2012.08.013.

[11] Etsion, I., Burstein, L. (1996). A model for mechanical seals with regular microsurface structure. Tribology Transactions, vol. 39, no. 3, p. 677-683, DOl:10.1080/10402009608983582.

[12] Rahmani, R., Rahnejat, H. (2018). Enhanced performance of optimised partially textured load bearing surfaces. Tribology International, vol. 117, p. 272-282, D0l:10.1016/j. triboint.2017.09.011.

[13] Maksimkin, A.V., Danilov, V.D., Senatov, F.S., Olifirov, L.K., Kaloshkin, S.D. (2017). Wear performance of bulk oriented nanocomposites UHMWPE/FMWCNT and metal-polymer composite sliding bearings. Wear, vol. 392-393, p. 167-173, D0l:10.1016/j.wear.2017.09.025.

[14] Wang, Y., Yin, Z., Li, H., Gao, G., Zhang, X. (2017). Friction and wear characteristics of ultrahigh molecular weight polyethylene (UHMWPE) composites containing glass fibers and carbon fibers under dry and water-lubricated conditions. Wear, vol. 380-381, p. 42-51, D0l:10.1016/j.wear.2017.03.006.

[15] Andersson, S., Söderberg, A. Björklund, S. (2007). Friction models for sliding dry, boundary and mixed lubricated contacts. Tribology International, vol., 40, no. 4, p. 580-587, D0I:10.1016/j.triboint.2005.11.014.

[16] Buckley, D.H. (1978). Tribological properties of surfaces. Thin Solid Films, vol. 53, no. 3, p. 271-283, D0l:10.1016/00406090(78)90221-3.

[17] El-Sayed, A.A., El-Sherbiny, M.G., Abo-El-Ezz, A.S., Aggag, G.A. (1995). Friction and wear properties of polymeric composite materials for bearing applications. Wear, vol. 184, no. 1, p. 4553, DOI:10.1016/0043-1648(94)06546-2.

[18] Ji, Z., Luo, W., Zhou, K., Hou, S., Zhang, Q., Li, J., Jin, H. (2018). Effects of the shapes and dimensions of mullite whisker on the friction and wear behaviors of resin-based friction materials. Wear, vol. 406-407, p. 118-125, D0l:10.1016/00431648(94)06546-2.

[19] Bin Masripan, N.A., Ohara, K., Umehara, N., Kousaka, H., Tokoroyama, T., Inami, S., Zushi, K., Fujita, M. (2013). Hardness effect of DLC on tribological properties for sliding bearing under boundary lubrication condition in additive-free mineral base oil. Tribology International, vol. 65, p. 265-269, D0I:10.1016/j.triboint.2013.01.016.

[20] Qiu, M., Chen, L., Yingchun, Li., Yan, J. (2017). Bearing Tribology - Principles and Applications. Springer Nature, Berlin.

[21] Street, K.W., Miyoshi, K., Vander Wal, R.L. (2007). Application of carbon based nano-materials to aeronautics and space lubrication. Erdemir, A., Martin, J.-M. (Eds.), Superlubricity. NASA, Cleveland, p. 311-340, Dol:10.1016/b978-0444527721/50050-0.

[22] Katana, B. (2017). Life time of composite bearing (doctoral thesis), University of Zagreb, Zagreb.

[23] Bijwe, J., Sen, S., Ghosh, A. (2005). Influence of PTFE content in PEEK-PTFE blends on mechanical properties and triboperformance in various wear modes. Wear, vol. 258, p. 15361542, D0l:10.1016/j.wear.2004.10.008.

[24] Norden Maritim. Marine Engineering Manual Rudder Bearing Design Guide, from https://www.nordenmaritim.no/, accessed on 2019-09-09.

[25] Domitran, Z., Žeželj, D., Katana, B. (2016). Influence of contact pressure and sliding speed on the temperature and coefficient of friction in sliding contact between two PET samples. Tehnicki Vjesnik - Technical Gazette, vol. 23, no. 2, p. 389-396, DOI:10.17559/TV-20151124163215.

[26] Myshkin, N.K., Petrokovets, M.l., Kovalev, A.V. (2005). Tribology of polymers: Adhesion, friction, wear, and masstransfer. Tribology International, vol. 38, no. 11-12, p. 910921, D0I:10.1016/j.triboint.2005.07.016.

[27] Shooter, K.V., Tabor, D. (1952). The Frictional Properties of Plastics. Proceedings of the Physical Society, Section B, vol. 65, p. 661-671, D0l:10.1088/0370-1301/65/9/302.

[28] Michaelis, K., Höhn, B., Hinterstoißer, M. (2011). Influence factors on gearbox power loss. Industrial Lubrication and Tribology, vol. 63, no. 1, p. 46-55, DOI:10.1108/00368791111101830. 
[29] Lin, L., Ecke, N., Kamerling, S., Sun, C., Wang, H., Song, X., Wang, K., Zhao, S., Zhang, J., Schlarb, A.K. (2018). Study on the impact of graphene and cellulose nanocrystal on the friction and wear properties of SBR/NR composites under dry sliding conditions. Wear, vol. 414-415, p. 43-49, DOI:10.1016/j.wear.2018.07.027.

[30] Saxena, P., Schinzel, M., Andrich, M., Modler, N. (2016). Development of a novel test-setup for identifying the frictional characteristics of carbon fibre reinforced polymer composites at high surface pressure. IOP Conference Series Materials Science and Engineering, vol. 149, p. 012124, DOI:10.1088/1757-899X/149/1/012124.

[31] Brockwell, K., DeCamillo, S. (1997). Performance Evaluation of the LEG tilting pad journal bearing, from www.kingsbury. com, accessed on 2019-09-09.

[32] Budynas, R., Nisbett, K. (2007). Shigley's Mechanical Engineering Design, McGraw-Hill, New York.

[33] Mao, K. (2007). A new approach for polymer composite gear design. Wear, vol. 262, no. 3-4, p. 432-441, D0l:10.1016/j. wear.2006.06.005.

\section{APPENDIX}
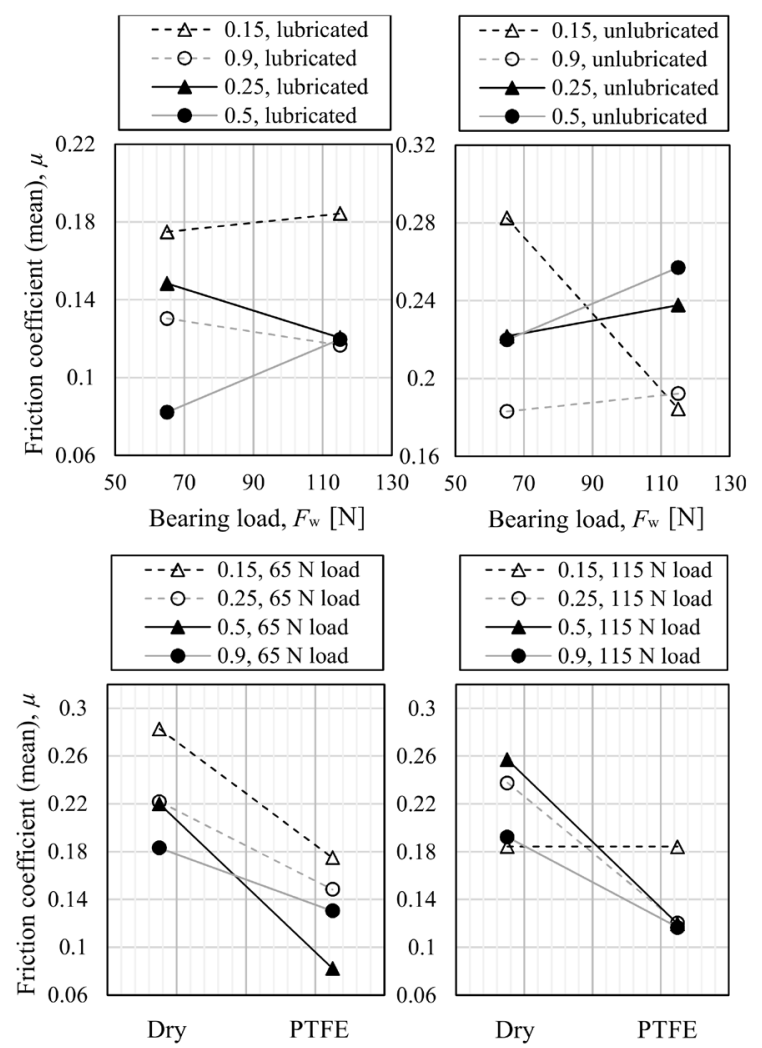

Fig. 7. Mean effect plot 